\title{
Calorimetric and Infrared Spectroscopic Analysis of Multiple Melting Endotherms of Poly(ethylene terephthalate)
}

\author{
Yong WANG, ${ }^{\dagger}$ Jin LU, and Deyan SHEN \\ Institute of Chemistry, The Chinese Academy of Sciences, Beijing 100080, China
}

(Received November 8, 1999)

\begin{abstract}
Multiple melting endotherms of poly(ethylene terephthalate) (PET) were investigated with differential scanning calorimetry (DSC), Fourier transition infrared spectroscopy (FT-IR) and temperature modulated DSC (MDSC) by examining PET samples subjected to special schemes of crystallization and annealing treatment at different temperatures. Upon one-step and two-step annealing, a series of multiple minor peaks in the PET were demonstrated by DSC. FT-IR showed that the multiple endothermic minor peaks were due to melting of imperfect crystals during crystallization. From MDSC curves direct evidence can be obtained for explanation the multiple melting mechanisms in these cold crystallized polymers. The morphology and melting mechanism of semicrystalline polymers depend on the thermal history of crystallization or annealing. When the sample is crystallized at an isothermal temperature or at multiple ascending temperatures, the hypothesis of melting of original low-temperature crystals and reorganization (recrystallization) into high-melt crystals during DSC scanning has been found responsible for the observed multiple melting behavior; when the sample is isothermally crystallized and annealed at multiple descending temperatures, the proposal of multiple morphologies is more responsible for the multiple melting peaks.
\end{abstract}

KEY WORDS Modulated Differential Scanning Calorimetry / Spectroscopic Analysis / Multiple Melting / Poly(ethylene terephthalate) / Annealing /

The melting behavior of isothermally crystallized thermoplastic semicrystalline polymers has been one of the most heavily studied projects in the field of polymer science. In general terms, the melting mechanism, usually analyzed by differential scanning calorimetry (DSC), manifests itself as multiple melting endotherms. Widely used semicrystalline engineering polymers, such as aliphatic polyamides (nylon) $)^{1,2}$ and poly(ethylene terephthalate) (PET) ${ }^{3-8}$ exhibit such multiple melting endotherms under certain crystallization/annealing conditions. The complexity of the DSC data for other polymers, such as Poly(butylene terephthalate) (PBT), ${ }^{9-12}$ isotactic polystyrene ${ }^{13}$ poly(ethylene 2,6 -naphthalenedicarboxylate)(PEN), ${ }^{14}$ and poly(vinylidene fluoride) $\left(\mathrm{PVF}_{2}\right){ }^{15}$ was also addressed and reported to exhibit similar behavior. Cold crystallization of these polymers nearly always results in a lower melting endotherm 10$20^{\circ} \mathrm{C}$ above the cold crystallization temperature, $T_{\mathrm{cc}}$, in addition to the higher melting endotherm whose position does not change much with $T_{c c}$. The lower melting endotherm shifts to higher temperature as $T_{\mathrm{cc}}$ increases.

Although the origin of the phenomenon has been the subject of intense research, its explanation still remains controversial. Because of the complexities in DSC data, many mechanisms have been proposed to explain findings. From the reported results, two main mechanisms, dual morphology $y^{10-12}$ and melting-recrystallizationremelting, ${ }^{16,17}$ have been proposed for the interpretation of multiple melting peaks. The dual morphology mechanism claims that two melting peaks in polymers might be explained by two different crystal populations. Stein and Misra, ${ }^{10}$ reported dual morphology, usual and unusual spherulites, in PBT and stated that the two DSC melting peaks arose from the melting of these two types of spherulites. The recrystallization-remelting mechanism proposes that crystals obtained at low crystalliza- tion temperatures have low degree of perfection and can partially melt and recrystallize during the course of thermal analysis scans to yield thicker and/or more perfect crystals. ${ }^{3-8}$ Todoki et al. ${ }^{16,17}$ claimed that the "dual melting peaks" were merely a "doublet appearance" of thermal behavior as a result of superposition of endothermic melting and exothermic recrystallization during DSC scanning. In other words, the crystals originally belong to a single population, but can undergo reorganization into a different population during heating processes. Lately, similar controversial arguments have been debated concerning high-temperature semicrystalline polymers such as poly(etherether ketone) (PEEK) ${ }^{18-20}$ and poly(phenylene sulfide) (PPS). ${ }^{21}$ By probing the multiple melting phenomenon and relationships with observed crystallization kinetics, Chen et al. ${ }^{22}$ provide evidence for the postulation of simultaneously existing lamellae of multiple thickness as a result of crystallization and annealing at multiple descending temperature steps.

This study was motivated by a belief that interpretation from another view angle could be provided by realizing that each of the two mechanisms might have only described some factual observations. To achieve more complete insight in explaining the phenomenon of the long controversial double (actually multiple) melting in semicrystalline polymers, we used conventional differential scanning calorimetry (DSC), Fourier transform infrared spectroscopy (FT-IR) and a new technique of temperature modulated differential scanning calorimetry (MDSC) to study the lower melting endotherm after a sequential annealing process. FT-IR, which is sensitive to molecular environment and structural conformation, has become an important tool in characterizing semicrystalline polymers. ${ }^{23}$ Through monitoring the change of conformations, we can understand the crystal- 
lizing and melting behavior during scanning. MDSC is a new measuring method in thermal analysis ${ }^{24-27}$ and overcomes some of limitations of conventional DSC, including the separation of complex, overlapping transitions into more easily interpreted components. ${ }^{25}$ A wide variety of applications have been reported since MDSC was first introduced in $1993 .^{24}$ By superimposing a sinusoidal temperature change, MDSC separates the "total" heat flow-such as that from conventional DSC-into two parts: heat flow from the heat capacity(reversible) effect that usually comes from glass transition relaxation or crystal melting; and heat flow from the non-heat capacity(non-reversible) effect that usually comes from enthalpic relaxation or cold crystallization. As a result one can get more information (especially from timedependent thermal events) than by conventional DSC.

This work further clarifies related issues on multiple melting behavior using the widely studied PET as a convenient model system for semicrystalline polymers. Both mechanisms (dual morphology and melting-recrystallization-remelting) are probably responsible for the observed multiple melting behavior dependent on the thermal histories.

\section{EXPERIMENTAL}

The semicrystalline polymer sample used was PET (Yanshan Corp., Beijing) in high-purity, additive-free forms. Amorphous PET films of ca. $10 \mu \mathrm{m}$ thickness were prepared by solution casting a $9 \%$ solution of PET in $\mathrm{CHCl}_{3}-\mathrm{CF}_{3} \mathrm{COOH}(4: 1 \mathrm{v} / \mathrm{v})$ onto glass plates at $70^{\circ} \mathrm{C}$. The cast films were air dried and then in vacuum at $40^{\circ} \mathrm{C}$ for $48 \mathrm{~h}$ to remove residual solvents. The films proved to be amorphous by density and FT-IR. ${ }^{28,29}$ PET samples A, B, C, D, E of different crystallinities were prepared by annealing amorphous PET films at: $185^{\circ} \mathrm{C}$ for $60 \mathrm{~min}$, $205^{\circ} \mathrm{C}$ for $60 \mathrm{~min}, 215^{\circ} \mathrm{C}$ for $60 \mathrm{~min}, 185^{\circ} \mathrm{C}$ for $60 \mathrm{~min}$ and then $205^{\circ} \mathrm{C}$ for $60 \mathrm{~min}, 205^{\circ} \mathrm{C}$ for $60 \mathrm{~min}$ and then $185^{\circ} \mathrm{C}$ for $60 \mathrm{~min}$, respectively. Various thermal treatments were conducted to confirm whether the multiple melting behavior was related to dual morphology or recrystallization/remelting mechanism.

\section{DSC Measurements}

A Perkin-Elmer DSC-4, was used to observe melting endothermic peaks. Baselines were adjusted to have maximum fluctuation of less than $0.1 \mathrm{~mW}$ over the temperature range of interest. The temperature and heat of melting were calibrated with a high purity indium standard. Relative small sample sizes $(\sim 4 \mathrm{mg})$ were used to minimize the effects of low thermal conductivity of the polymers. The polymer samples were scanned from $60^{\circ} \mathrm{C}$ to approximately $50^{\circ} \mathrm{C}$ above the respective melting temperature of each polymer. A rate of $10^{\circ} \mathrm{C} \mathrm{min}^{-1}$ scan rate was selected in all experiments unless otherwise indicated.

\section{FT-IR Measurements}

Infra-red spectra in the region $750-1650 \mathrm{~cm}^{-1}$ were recorded on a Perkin Elmer System 2000 FT-IR instrument under standard operating conditions. For in situ measurements during a temperature scan from $60-270$ ${ }^{\circ} \mathrm{C}$ the specimen was held in the heating cell, the heating rate being $1{ }^{\circ} \mathrm{C} \min ^{-1}$. The spectra were taken for every $2^{\circ} \mathrm{C}$ increase, and each spectrum was the average of 20 scans at a resolution of $4 \mathrm{~cm}^{-1}$. The measurement time per each spectrum was about $50 \mathrm{~s}$.

\section{MDSC Measurements}

Principle of Measurements. MDSC experiments were performed on the TA Instruments Thermal Analysis 2100 system using a 2920 Modulated DSC (MDSC ${ }^{\mathrm{TM}}$ ). In MDSC, sinusoidal temperature change is superimposed on the standard linear temperature ramp. As a result, there are three heating-related experimental variables to improve DSC results: heating rate, amplitude of modulation, and frequency of modulation. To evaluate the effects these variables can have, the general equation describing calorimeter response such as,

$$
\mathrm{d} Q / \mathrm{d} t=-\mathrm{d} T / \mathrm{d} t\left\{\mathrm{C} p+f^{\prime \prime}(t, T)\right\}+f(t, T)
$$

where $\mathrm{d} Q / \mathrm{d} t$-heat flow out of the sample, $\mathrm{d} T / \mathrm{d} t$-heating rate, $C p$-sample heat capacity, $t$-time, $T$-temperature, $f^{\prime \prime}(t, T)$-thermodynamic heat flow components, and $f(t$, $T$ )-kinetically limited heat flow.

This equation shows that total heat flow comprises two contributions, one is heating-rate dependent and the other, dependent only on absolute temperature. The relative effect of these two contributions varies depending on the transition. Heating-rate dependent transitions tend to be large when evaluated using higher heating rates and are 'reversing'; i.e., the transition can be cycled by alternating heating and cooling. Absolute temperature dependent transitions, once initiated cannot be reversed by cyclic heating/cooling and are considered 'nonreversing'. With such calorimeters, the application of this measuring principle for many different materials within a wide temperature range is possible. As a result one can get more information (especially from timedependent thermal events) than by conventional DSC.

Calorimetry Conditions. Temperature and baseline were calibrated as in conventional DSC. Unless indicated, a scan rate of $4^{\circ} \mathrm{C}$ min $^{-1}$ was used with a temperature modulation amplitude of $0.42^{\circ} \mathrm{C}$ and oscillation period of $40 \mathrm{~s}$. To maximize the signal as well as reduce heat transfer delay, an average sample weight of $10 \mathrm{mg}$ was used. The weights of the sample and reference pans are carefully matched. $\mathrm{N}_{2}$ was used as a heat transfer gas at a flow rate of $30 \mathrm{~mL} \min ^{-1}$. For each sample, three MDSC experiments at $4^{\circ} \mathrm{C} \mathrm{min}^{-1}$ were performed to test reproducibility.

\section{RESULTS AND DISCUSSION}

Figure 1 shows conventional DSC curves scanned at $10^{\circ} \mathrm{C} \mathrm{min}^{-1}$ of PET samples quenched from the melt state and subjected to isothermal crystallization at different temperatures. Sample A crystallized at $185^{\circ} \mathrm{C}$ shows a melting point at $255^{\circ} \mathrm{C}$, and a minor peak is observed just above the crystallization temperature, $T_{\mathrm{cc}}$. The melting behavior of PET is strongly dependent on crystallization history, as shown in Figure 1. With increasing $T_{\text {cc }}$, the minor peak shifts to higher temperature, but the major melting peak remains constant and independent of the crystallization temperature. The in- 


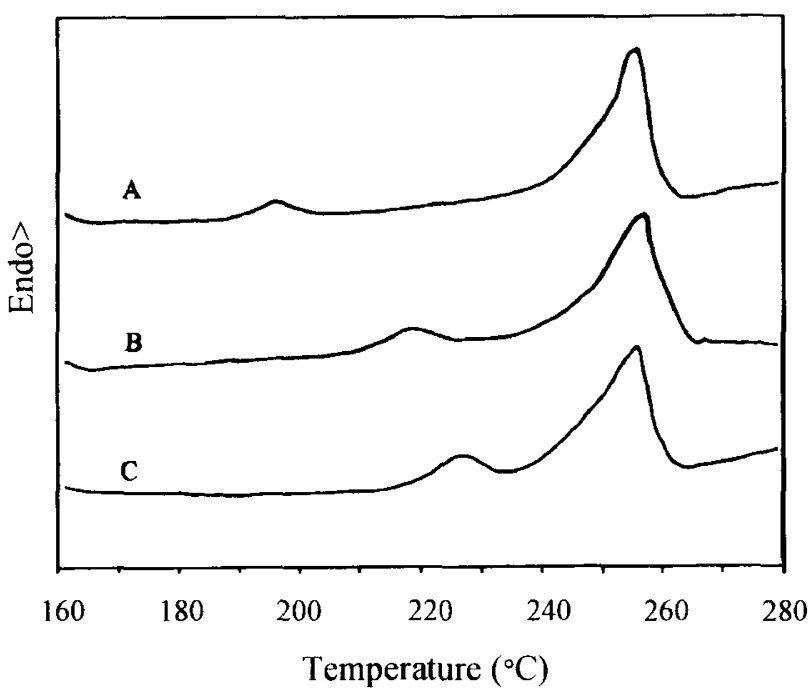

Figure 1. DSC curves for the three samples of PET with different thermal histories. Amorphous samples annealed at (A) $185^{\circ} \mathrm{C}$ for $1 \mathrm{~h}$; (B) $205^{\circ} \mathrm{C}$ for $1 \mathrm{~h}$; (C) $215^{\circ} \mathrm{C}$ for $1 \mathrm{~h}$.

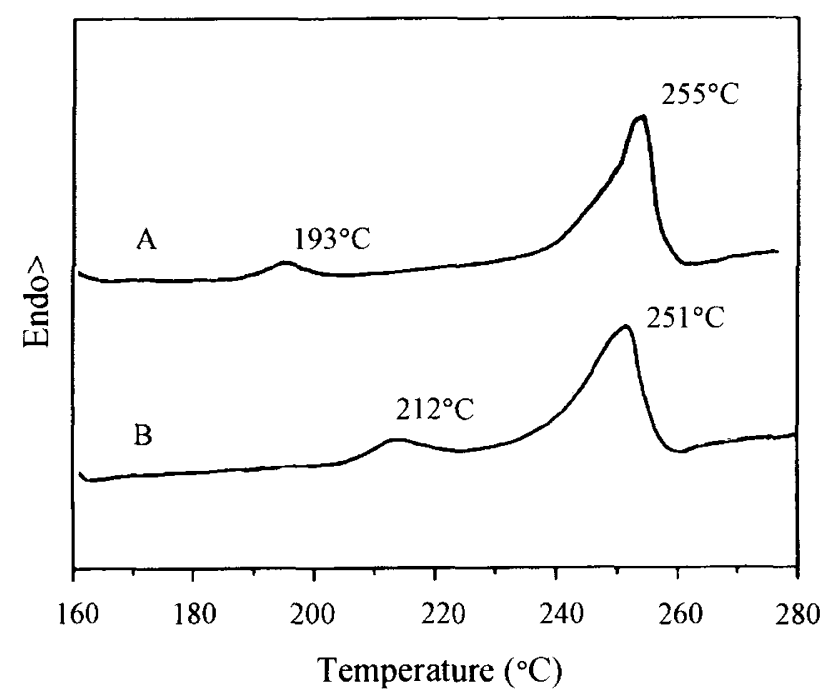

Figure 2. DSC curves for the sample $A$ annealed at $185^{\circ} \mathrm{C}$ for $1 \mathrm{~h}$

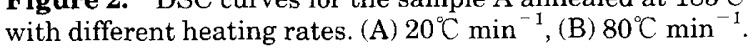

tensity of this minor peak also changes with heating rate. The effect of heating rate on melting peaks is shown in Figure 2. In both figures, it should be noted that the shape of the main upper peak remains unchanged as a result of isothermal treatment. The lower peak appears as a movable superimposed feature on the side of the main peak. The positions of the two peaks are labeled on the curves. DSC data at different heating rates show the expected trend ${ }^{3-8,30}$ with the positions of the two peaks shifting in opposite directions. The lower endotherm position increases by a few degrees, whereas the main upper peak moves downwards by several degrees. According to Blundell and Lee et al., ${ }^{30,31}$ these facts can be reconciled to the continuous melting/recrystallization mechanism. The shift in the endotherm is due to the different extent of recrystallization at different heating rate.$^{30,31}$ However, the data again reinforce the complications of conventional DSC and modification of the sample during scan.

The samples subjected to annealing or isothermal

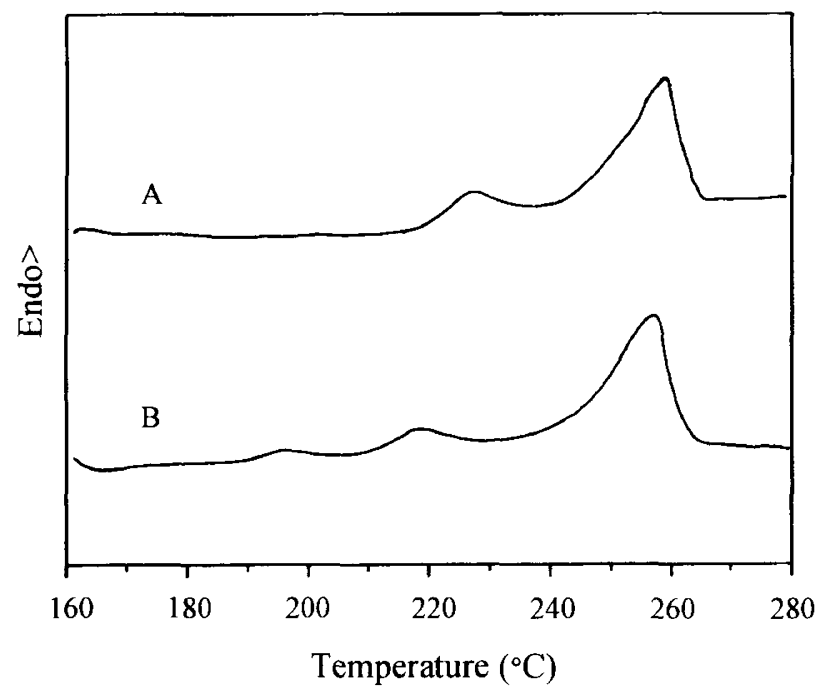

Figure 3. DSC curves for the samples of PET with different thermal histories. Amorphous samples step-annealed at (A) $185^{\circ} \mathrm{C}$ for $1 \mathrm{~h}+205^{\circ} \mathrm{C}$ for $1 \mathrm{~h}$; (B) $205^{\circ} \mathrm{C}$ for $1 \mathrm{~h}+185^{\circ} \mathrm{C}$ for $1 \mathrm{~h}$.

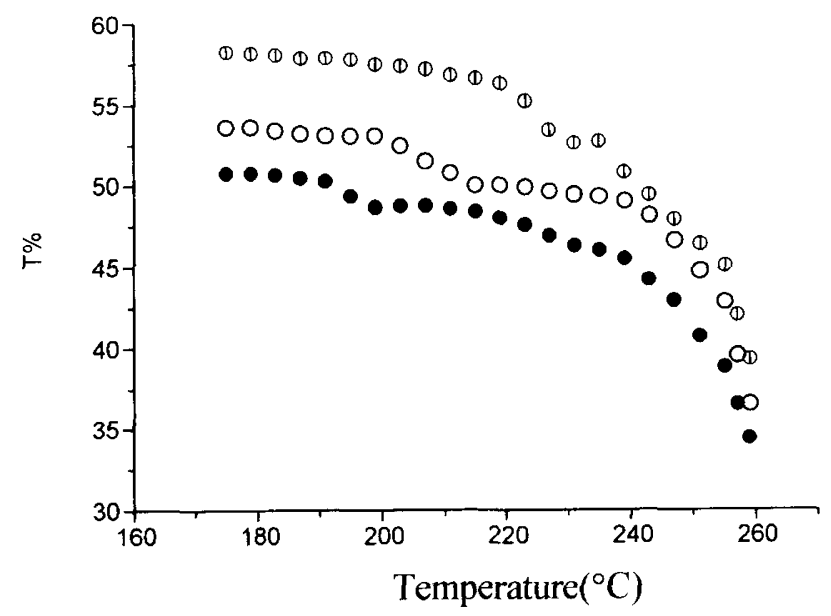

Figure 4. Changes of the fraction of trans conformers $(T \%)$ as a function of temperature for the three samples of PET with different thermal histories. Amorphous samples annealed at (O) $185^{\circ} \mathrm{C}$ for $1 \mathrm{~h}$; (O) $205^{\circ} \mathrm{C}$ for $1 \mathrm{~h}$; (D) $215^{\circ} \mathrm{C}$ for $1 \mathrm{~h}$.

crystallization in two-step also exhibited minor melting peaks in the low temperature range. Figure 3 shows DSC curves scanned at $10^{\circ} \mathrm{C} \mathrm{min}^{-1}$ demonstrating the melting behavior of two-step annealed samples. For the sample crystallized in two ascending steps $\left(185^{\circ} \mathrm{C}\right.$ for $1 \mathrm{~h}$ $+205^{\circ} \mathrm{C}$ for $1 \mathrm{~h}$ ), only a minor peak was observed, corresponding to that of the one-step crystallization at the higher of the two steps, and its DSC curve was similar to the one of the higher temperature annealing samples (B in Figure 1). Another sample crystallized at two descending isothermal steps $\left(205^{\circ} \mathrm{C}\right.$ for $1 \mathrm{~h}+185^{\circ} \mathrm{C}$ for $\left.1 \mathrm{~h}\right)$, but two minor peaks were seen located at $197^{\circ} \mathrm{C}$ and 218 ${ }^{\circ} \mathrm{C}$, in addition to the main melting peak at $255^{\circ} \mathrm{C}$. The minor peak at the higher isothermal crystallization temperature tended to be stronger.

\section{IR Spectroscopic Studies}

To probe explanations for the origin of these minor peaks, an in situ FT-IR method was used during increasing temperature. In semicrystalline $\mathrm{PET}$, the $-\mathrm{O}-\mathrm{CH}_{2}-$ 


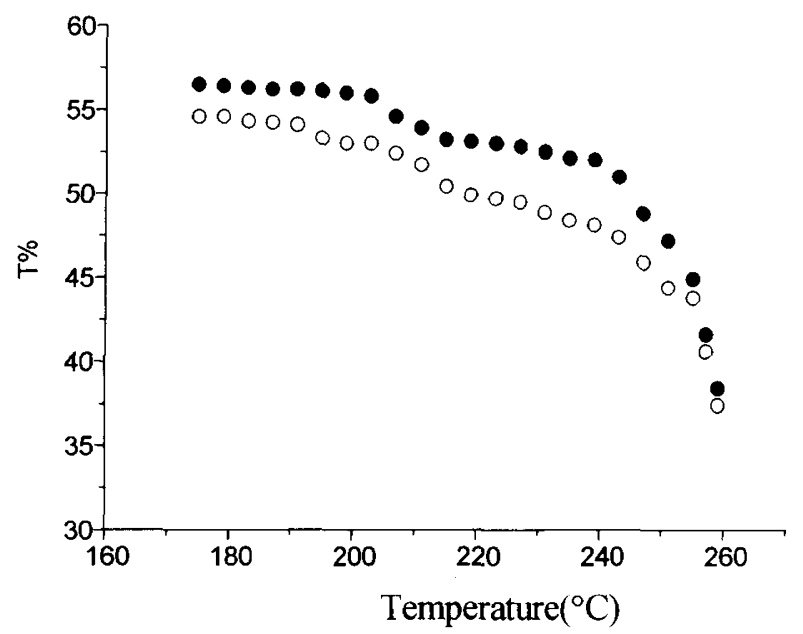

Figure 5. Changes of the fraction of trans conformers $(T \%)$ as a function of temperature for the samples of PET with different thermal histories. Amorphous samples step-annealed at $(O) 185^{\circ} \mathrm{C}$ for $1 \mathrm{~h}+205^{\circ} \mathrm{C}$ for $1 \mathrm{~h} ;(\bigcirc) 205^{\circ} \mathrm{C}$ for $1 \mathrm{~h}+185^{\circ} \mathrm{C}$ for $1 \mathrm{~h}$

$\mathrm{CH}_{2}-\mathrm{O}$ - moiety of a chain adopts trans conformation in the crystalline regions, while in amorphous regions it is mainly in gauche conformation with a small contribution of trans conformation. In infrared spectra of PET, the $1340 \mathrm{~cm}^{-1}$ and $1370 \mathrm{~cm}^{-1}$ bands have been assigned to the $\mathrm{CH}_{2}$ wagging mode in trans and gauche conformers, respectively. ${ }^{33}$ The absorbance of $1340 \mathrm{~cm}^{-1}$ increased significantly during crystallization, and its intensity reflects molecular conformational change of PET. In this paper we choose these two bands (1340 and 1370 $\mathrm{cm}^{-1}$ ) as key bands for determining relative conformational populations. The fraction of $\operatorname{trans}(T)$ conformer can be obtained by $T=A_{1340} /\left(A_{1340}+6.6 \times A_{1370}\right) .{ }^{28,29} \mathrm{By}$ in situ FT-IR, through measuring the band intensity changes, we can understand conformational change of PET molecules and thus study the lower endothermic peaks of crystalline PET at molecular level.

Changes of the fraction of trans conformers $(T \%)$ as a function of temperature from measured $A_{1340}$ and $A_{1370}$ of PET with different crystallization temperatures are shown in Figure 4. The fraction of trans conformers of samples A, B, C took abrupt changes at nearly $195^{\circ} \mathrm{C}$, $210^{\circ} \mathrm{C}$, and $224^{\circ} \mathrm{C}$ respectively during temperature increase and decreased steeply near the respective melting points of these samples. The results of molecular conformational change were correlated with those small endothermic peaks of crystalline PET. The minor endothermic peak in DSC and a step decrease of T\% are probably related to the melting of crystals. It is of interest that in the sample A $T \%$ increased slightly after a steplike decrease. The reason for this is that the heating rate $\left(1^{\circ} \mathrm{C}\right.$ $\min ^{-1}$ ) was so slow that there would be enough time for melted chains to recrystallize into higher-melt crystals. That is, much of the imperfect crystalline structure melted while some of it formed more perfect crystal through recrystallization.

For the two-step annealed samples, behavior similar to DSC scan results was observed (Figure 5). In the sample annealed at ascending isothermal steps, a comparison of trans conformation changes on heating of sample $A$ and $D$ indicates that the conformation defect that melts at $185^{\circ} \mathrm{C}$ in A was removed by the second step an-

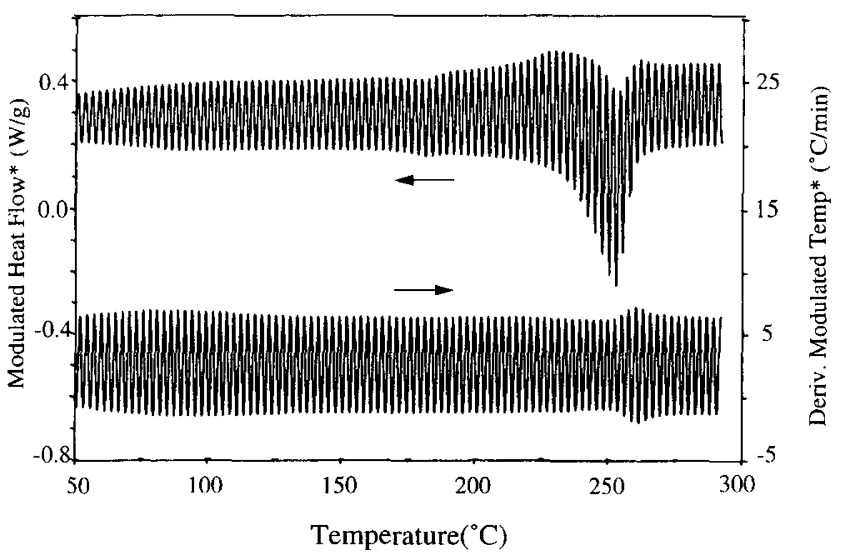

Figure 6. MDSC raw data from the sample A. The upper curve represents the modulated heat flow, and the lower curve represents the actual heating rate.

nealing at $205^{\circ} \mathrm{C}$. There exists a melting course at the second annealing step and at the same time the imperfect crystal formed in the first-step changes into more perfect crystal when annealed at higher temperature, so that the conformation changes of $\mathrm{B}$ and $\mathrm{D}$ on heating are almost identical. But when annealed at descending temperature steps, there are two abrupt trans conformation changes correlated with two small endothermic peaks in DSC curve. This indicates that the different crystals may independently exist in PET. The multiple minor peaks probably originate from the melting of the imperfect crystalline regions.

\section{Further Modulated DSC Studies}

In Figure 6, MDSC raw data obtained from the sample A are presented. The upper curve gives the modulated heat flow, while the lower curve shows the simultaneous heating rate. Almost at all times, the heating rate is above zero; $i$. e., the sample does not experience cooling. The heat flow curves can be derived from these raw data. The results are shown in Figures $7 \mathrm{a}, 7 \mathrm{~b}$, and $7 \mathrm{c}$ for A, B, C samples and Figures $8 \mathrm{a}$ and $8 \mathrm{~b}$ for $\mathrm{D}, \mathrm{E}$, respectively. Each plot consists of three curves, representing reversing heat flow $(\mathrm{R})$, total heat flow $(\mathrm{T})$ and nonreversing heating flow (NR), respectively. The total heat flow ( $\mathrm{T}$ ) curve shows total thermal response of the sample, and provides the same level of information as in normal DSC. Similar results in Figures 1 and 3 are observed in the total heat flow curves of Figures 7 and 8 . To separate thermal history effects, we must compare the two other heat flow curves, $R$ and NR, that represent different physical processes.

From the reversing heat flow $(\mathrm{R})$ curve shown in Figure 7, sample A shows a broad glass transition, an endothermic step and a melting endotherm. For samples B and $\mathrm{C}$, the endothermic step shifts to a higher temperature as increasing $T_{\mathrm{cc}}$, while the major melting peak stays at the same temperature. Obviously, the endothermic step may represent the lower melting peak. Many features not accessible through normal DSC can be observed in the NR curves. First, cold crystallization exotherms are observed for all samples as shown in Figure 7. The NR curve in Figure 7 verifies the suspected recrystallization where a exotherm is seen starting as soon as the temperature of the scan exceeds the tem- 


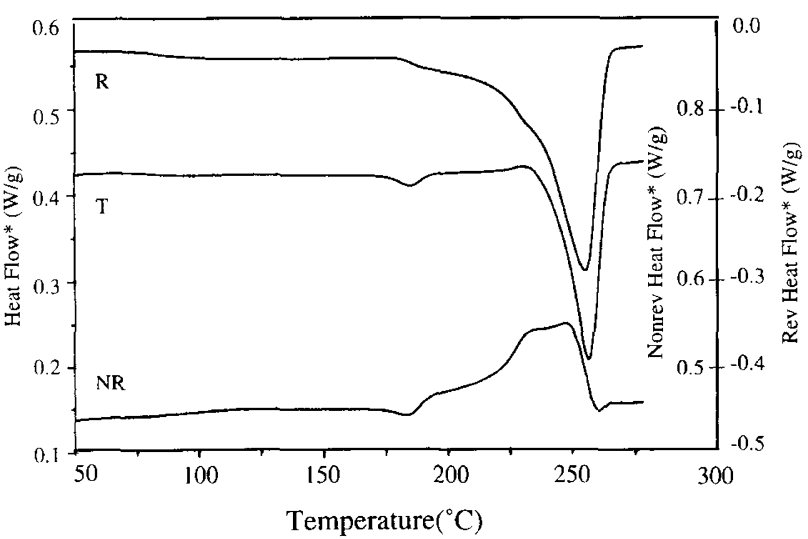

(a)

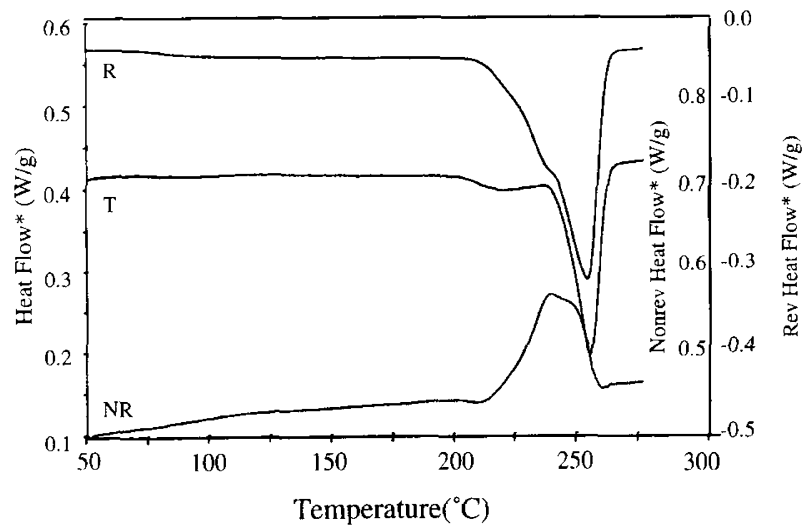

(b)

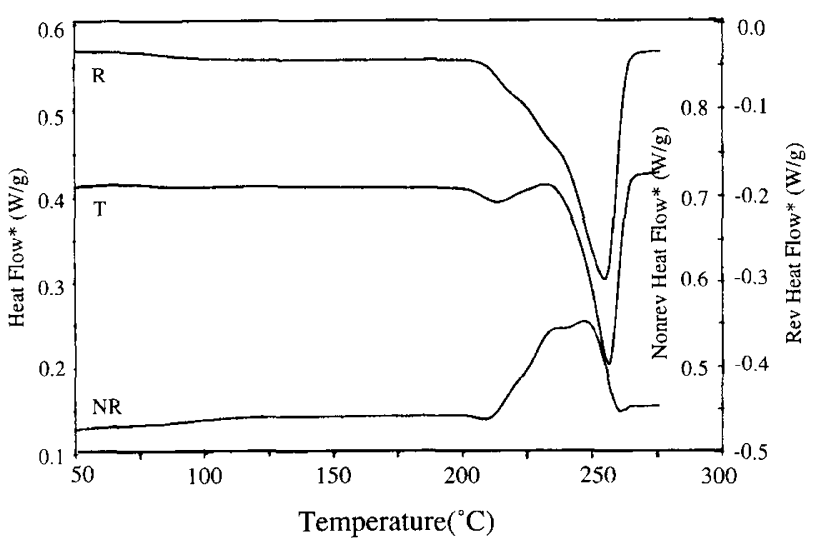

(c)

Figure 7. MDSC curves obtained at a heating rate of $4^{\circ} \mathrm{C}$ min ${ }^{-1}$ for the three samples of PET with different thermal histories. Amorphous samples annealed at (a) $185^{\circ} \mathrm{C}$ for $1 \mathrm{~h}$; (b) $205^{\circ} \mathrm{C}$ for $1 \mathrm{~h}$; (c) $215^{\circ} \mathrm{C}$ for $1 \mathrm{~h}$

perature to which the samples had been exposed. This indicates that the materials continued to recrystallize as the temperature increased. For sample A initially cold crystallized at $185^{\circ} \mathrm{C}$, we observed changes in R and NR curves when the scanning temperature reaches $185^{\circ} \mathrm{C}$. The step-like transition in the $R$ curve indicates the start of melting of crystals formed at the treatment temperature. At the same time, the exotherm in the NR curve indicates that continuous recrystallization and reorganization take place during scanning. The shapes of these endotherms cannot be clearly distinguished from normal DSC studies, or from the total heat flow (T)

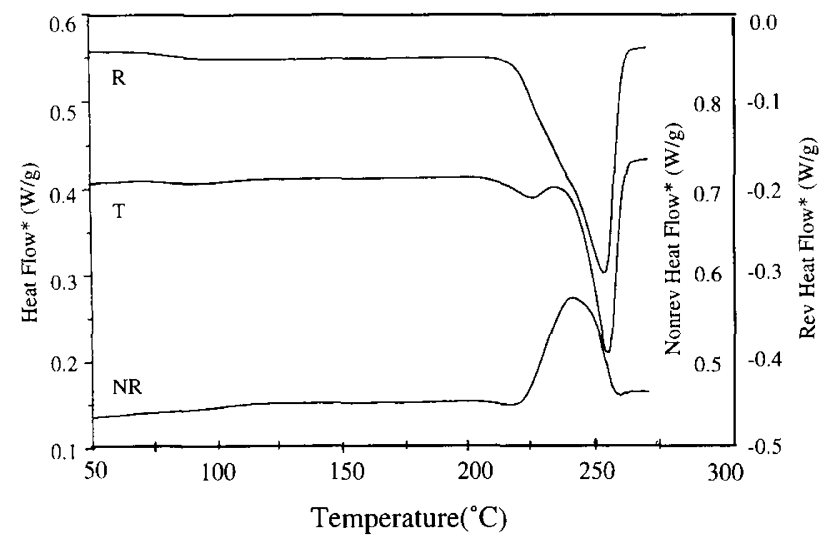

(a)

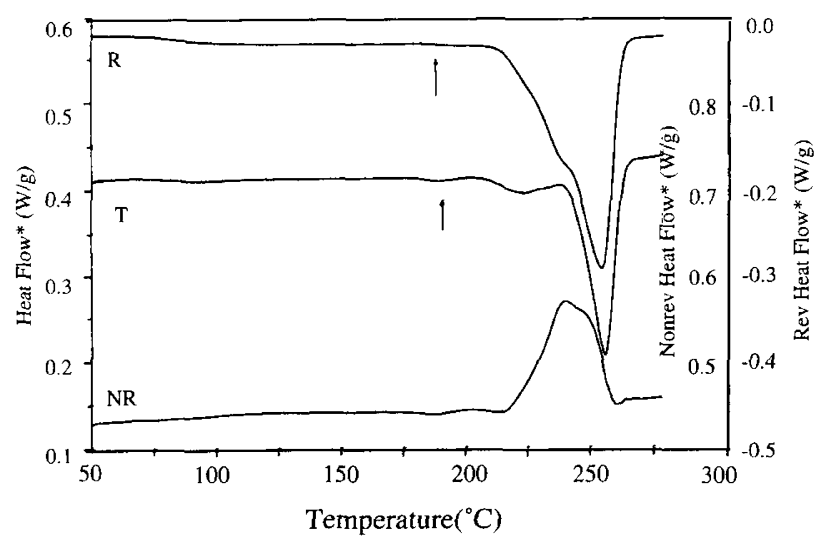

(b)

Figure 8. MDSC curves obtained at a heating rate of $4{ }^{\circ} \mathrm{C} \mathrm{min}{ }^{-1}$ for the two samples of PET with different thermal histories. Amorphous samples step-annealed at (a) $185^{\circ} \mathrm{C}$ for $1 \mathrm{~h}+205^{\circ} \mathrm{C}$ for $1 \mathrm{~h}$; (b) $205^{\circ} \mathrm{C}$ for $1 \mathrm{~h}+185^{\circ} \mathrm{C}$ for $1 \mathrm{~h}$.

curves in MDSC since endo- and exothermic responses occur in additive contribution. It is clear that MDSC is a very powerful new tool to quantify the onset temperature and extent over which recrystallization occurs. Here, we suggest that the lower endotherm seen in normal DSC and here in the $R$ curves, accordingly marks the point where the original isothermally formed crystals become unstable and where the onset of melting and recrystallization occurs. From the above MDSC results, it is clear that the multiple peaks are related to a melting and recrystallization phenomenon of one initial crystal morphology, which is characteristic of the prior crystallization history. The lower peak is indicative of the onset of the melting of the characteristic crystals. In the interval between the peaks, all the molecules experience continuous melting and recrystallization. The upper peak indicates the point at which the net difference between melting and recrystallization passes through a maximum, which verifies that the upper endotherm in the sample is due to reorganized crystals formed during the heating scan. With increase of annealing temperature, the previously formed crystals isothermally thicken to become more stable entities, so that the onset of melting/recrystallization at the first DSC peak occurs at higher temperature and will become more pronounced.

However, the phenomena shown by two-step annealed samples do not always support the origin of the minor peaks in reorganization during scanning. Figure 8 shows 
MDSC curves demonstrating the melting behavior of two-step annealed samples. Sample D crystallized at two ascending isothermal steps, a minor peak is seen in its total heat flow curve, while the sample E crystallized at two descending steps, two minor peaks were observed, which are the same as their normal DSC curves. In the $\mathrm{R}$ curves, sample $\mathrm{D}$ shows a small endothermic step located at about $208^{\circ} \mathrm{C}$, while sample E shows two small endothermic steps located at $188^{\circ} \mathrm{C}, 212^{\circ} \mathrm{C}$, respectively. In the NR curves, cold crystallization exotherms were observed for the two samples. For sample D, crystal reorganization occurs when the temperature exceeds the higher annealing temperature of the second step. It is interesting to note that for sample $\mathrm{E}$, the lower minor peak only melted without crystal reorganization, suggesting the independence of the minor endotherm at 190 ${ }^{\circ} \mathrm{C}$ from the other peaks. The exothermic heat flow starts only when the temperature of the scan exceeds the higher annealing temperature $\left(T_{\mathrm{cc}}\right)$ to which the samples had been exposed in two-step annealing. This suggests that the minor crystal entities for this lower minor peak may be indeed in coexistence with simultaneous existing crystal entities of melting peak. In other words, the melting of the minor crystal at $190^{\circ} \mathrm{C}$ is independent and has nothing to do with the appearance of the other melting peaks. That is, different components of the morphology in PET, in the form of multiple lamellar distributions are responsible for the multiple melting phenomena.

Analysis of MDSC scans in the melting region is still a subject of intense debate. ${ }^{32}$ Nonetheless, we may compare the relative behavior of these materials treated with the same MDSC protocol. Although instrumental thermal lag may change the appearance of reversing and non-reversing heat flow curves, we expect these effects to be similar for samples of similar mass. Therefore, changes seen in the reversing and non-reversing heat flow curves may tentatively be identified with real behavior of the materials.

From above results it is worth pointing out that for one-step isothermal crystallization, reorganization was observed right above $T_{\mathrm{cc}}$ as indicated by the exothermic peaks observed in the NR curves. Since cold crystallization results in small and imperfect crystals, once the samples have been melted at higher temperature, they tend to form more perfect crystals that are stable at higher temperature. For the ascending two-step isothermal crystallization, the lower melting crystals formed during the first isothermal crystallization melt on heating to the second crystallization step. Recrystallization occurs and leads to the new low-temperature minor peak governed by the higher $T_{\text {cc }}$ of the second step. In these cases, the lower endotherm is not a true "endotherm", but a superposition of early melting of imperfect crystals with almost simultaneous exothermic recrystallization. These MDSC results directly support the theory of reorganization in the polymer cold crystallized the quenched amorphous state. For the descending two-step isothermal annealing, crystallization followed by annealing at lower temperature yields much thinner lamellae. The Hoffman's equation ${ }^{34}$ gives:

$$
T_{\mathrm{m}}=T_{\mathrm{m}}^{0}\left(1-\frac{2 \sigma_{e}}{\Delta H_{\mathrm{f} .} L}\right)
$$

where $T_{\mathrm{m}}^{0}$ is the melting point of an infinite perfect crystal, $\sigma_{e}$ is the surface energy of the crystals, $\Delta H_{\mathrm{f}}-$ the heat of fusion, $L$-the lamellar crystal thickness. The equation indicates lower melting points for lamellae of smaller $L$. Our results suggest that lamellae develop to different thickness at descending temperatures, and those of smaller thickness would melt at lower temperature. The multiple melting phenomenon of PET is associated with multiple populations of minor crystal aggregates.

\section{CONCLUSIONS}

The multiple melting behavior of PET was investigated with DSC, FT-IR and temperature modulated DSC by examining PET samples subjected to special schemes of crystallization and annealing treatment at different temperatures. Upon one-step and two-step annealing, a series of multiple minor peaks in the PET were demonstrated by DSC. By following changes in conformation population during heating, in situ FT-IR results showed that the multiple endothermic minor peaks were due to melting of imperfect crystalline conformation during crystallization. The crystalline conformational defects change into more perfect ones when annealing at higher temperatures. From MDSC curves direct evidence is obtained for the occurrence of crystal reorganization recrystallization in these one-step cold crystallized polymers. Reorganization takes place immediately when the sample temperature reaches the previous treatment temperature. The lower minor DSC peak accordingly marks the point where the original isothermally formed crystals become unstable and where the onset of melting and recrystallization occurs. From the multiple melting peaks in step-wise annealed PET, when the sample is crystallized at multiple ascending temperatures after quenching from the melt state, the semicrystalline polymer undergoes further crystallization upon heating in DSC, so that the onset of melting/ recrystallization at the first peak occurs at higher temperature. However, when the sample is isothermally crystallized and annealed at multiple descending temperatures, the low-temperature minor crystals simply melt but do not re-organize into higher-melt crystals during scanning. Multiple melting peaks were observed by thermal scanning, and a multiple lamellae population might likely exist. It is concluded that the morphology and melting mechanism of semicrystalline polymers depend on the thermal history of crystallization or annealing. When the sample is crystallized at an isothermal temperature or at multiple ascending temperatures, the hypothesis of melting of original low-temperature crystals and reorganization into high-melt crystals during DSC scanning has been found responsible for the observed multiple melting behavior. When the sample is isothermally crystallized and annealed at multiple descending temperatures, the multiple morphologies are more responsible for the multiple melting peaks. 


\section{REFERENCES}

1. J. P. Bell, P. E. Slade, and J. H. Dumbleton, J. Polym. Sci., A-2, 6, 1773 (1968).

2. A. Xenopoulos and B. Wunderlich, J. Polym. Sci., Polym. Phys. Ed., 28, 2271 (1990).

3. P. Holdsworth and A. Turner-Jones, Polymer, 12, 195 (1971).

4. G. C. Alfonso, E. Pedemonte, and L. Ponzetti, Polymer, 20, 104 (1979)

5. G. E. Sweet and J. P. Bell, J. Polym. Sci., A-2, 10, 1273 (1972).

6. S. B. Lin and J. L. Koenig, J. Polym. Sci., Polym. Phys. Ed., 21, 2365 (1983).

7. F. Fountain, J. Ledent, G. Groeninckx, and H. Reynaers, Polymer, 23, 185 (1982).

8. R. C. Roberts, Polymer, 10, 117 (1969).

9. S. Y. Hobbs and C. F. Pratt, Polymer, 16, 462 (1975).

10. R. S. Stein and A. Misra, J. Polym. Sci., Polym. Phys. Ed, , 18, 327 (1980).

11. J. T. Yeh and J. Runt, J. Polym. Sci., Polym. Phys. Ed., 27, 1543 (1989).

12. H. J. Ludwig and P. Eyerer, Polym. Eng. Sci., 28, 143 (1988).

13. J. Boon, G. Challa, and D. W. Krevelen, J. Polym. Sci., Polym. Phys. Ed., 16, 1791 (1968).

14. S. Wang, D. Y. Shen, and R. Y. Qian, J. Appl. Polym. Sci., 60, 1385 (1996).

15. W. M. Prest Jr. and D. J. Lucas, J. Appl. Phys., 46, 4136 (1975).
16. M. Todoki and T. Kawaguchi, J. Polym. Sci., Polym. Phys Ed., 15, 1067 (1977)

17. J. Kim, M. E. Nichols, and R. E. Robertson, J. Polym. Sci., Polym. Phys. Ed., 32, 887 (1994)

18. D. C. Bassett, R. H. Olley, and A. R. Iam, Polymer, 29, 1745 (1988).

19. P. Cebe and S. D. Hong, Polymer, 27, 1183 (1986).

20. H. Marand and A. Prasad, Macromolecules, 25, 1731 (1992).

21. J. Chung and P. Cebe, Polymer, 33, 2313 (1992).

22. C. Y. Chen and E. M. Woo, Polym. J., 27, 361 (1995).

23. L. D'Esposito and J. L. Koenig, J. Polym. Sci., Polym. Phys. Ed., 14, 1731 (1976).

24. M. Reading, Trends Polym. Sci., 1, 248 (1993).

25. P. S. Gill, S. R. Sanerbrunn, and M. Reading, J. Therm. Anal., 40, 931 (1993).

26. M. Reading, A. Luget, and R. Wilson, Thermochim. Acta, 238, 295 (1994).

27. D. J. Hourston, M. Song, A. Hammiche, H. M. Pollock, and M. Reading, Polymer, 37, 243 (1996).

28. R. Y. Qian, D. Y. Shen, and F. G. Sun, Macromol. Chem. Phys., 197, 1485 (1996).

29. Y. Wang, D. Y. Shen, and R. Y. Qian, J. Polym. Sci., Polym. Phys. Ed., 36, 783 (1998)

30. D. J. Blundell, Polymer, 28, 2248 (1987).

31. Y. Lee and R. S. Porter, Macromolecules, 20, 1336 (1987).

32. A. Miyake, J. Polym. Sci., 38, 479 (1959).

33. W. Sichina, in Proc. NATAS Conf., 24th, 133 (1995).

34. B. Wunderlich, "Macromolecular Physics", Vol. 3, Academic, New York, N. Y., 1980 